\title{
Uma mulher no espaço político: Um estudo comparativo entre as representações fotográficas de Dilma Roussef e Aécio Neves na mídia tradicional brasileira
}

\author{
Natalia Reis Gomes \\ Universidade de Coimbra - nataliareisgomes1@gmail.com
}

\begin{abstract}
Resumo
Este artigo apresenta uma análise comparativa das representações fotográficas da presidenta brasileira Dilma Roussef e do candidato à presidência Aécio Neves na Revista IstoÉ. Tendo como base a Análise Crítica do Discurso e os processos semióticos de conotação buscamos compreender quais preconceitos de gênero foram relacionados às imagens fotográficas de Dilma e de Aécio. A análise identificou estereótipos visuais vinculados ao não pertencimento feminino aos espaços

públicos de poder, a racionalidade masculina em contraste com a histeria feminina, a vulnerabilidade e solidão das mulheres políticas e vinculações de Dilma à figura de bruxa. A análise expôs o tratamento desigual que Dilma Rousseff recebeu de parte da mídia brasileira ao desafiar os papéis tradicionais de gênero. A violência simbólica que sofreu quando ocupou o mais importante cargo do poder executivo marcarão a história do Brasil como uma retaliação midiática massiva.
\end{abstract}

Palavras-chave: mídia, gênero, representações fotográficas, estereótipos.

\section{A woman in the political space: A comparative study between the photographic representations of Dilma Roussef and Aécio Neves in traditional Brazilian media}

\begin{abstract}
This article presents a comparative analysis of the photographic representations of Brazilian president Dilma Roussef and presidential candidate Aécio Neves in IstoÉ magazine. Based on the Critical Discourse Analysis, we seek to understand which gender prejudices were related to the photographic images of

Dilma and Aécio. The analysis identified visual stereotypes linked to female non-belonging to public spaces of power, male rationality in contrast to female hysteria, the vulnerability and loneliness of political women and Dilma's links to the witch figure. The analysis exposed the unequal treatment that Dilma
\end{abstract}

(C) do(s) Autor(s) 2021. Artigo publicado online, em acesso aberto, por Interações: Sociedade e as Novas Modernidades, ISSN: 2184-3929, em https://interacoes-ismt.com, nos termos da Licença Internacional Creative Commons Attribuiçao-NãoCommercial 4.0 (https://creativecommons.org/ 
Uma mulher no espaço político: Um estudo comparativo entre as representações

fotográficas de Dilma Roussef e Aécio Neves na mídia tradicional brasileira

Rousseff received from part of the Brazilian media in challenging traditional gender roles. The symbolic violence she suffered when she held the most important post in the executive branch will mark Brazil's history as a massive media retaliation.

Keywords: media, gender, photographic representations, stereotypes.

\section{INTRODUÇÃo}

Podemos definir mídia como tudo que envolve a produção e a transmissão de informações e de bens culturais, em processos que possibilitam a formação de opinião, interação e socialização entre os indivíduos (Lima, 2001). E justamente pela participação social essa produção não é neutra e não se constrói fora de um sistema de interesses, sendo imbricada de valores, subjetividades e simbologias que refletem o mundo real (Briggs \& Burke, 2016). Nestas produções midiáticas se encontram as representações sociais, que servem de guia para a sociedade, moldando comportamentos. Dentro destas representações, a fotografia ganha grande força como um veículo do poder ou da ideologia dominante (Toral, 2001) pois as representações fotográficas e a comunicação visual carregam diversos sentidos sociais (Ledin \& Machin, 2018). Parte dessa força diz respeito às crenças sencientes de uma transparência do discurso fotográfico dentro do mundo visual (Walton, 1984). O testemunho do trabalho fotográfico tem, no geral, valor de prova irrefutável.

Para Volosinov (1986, p. 10), todo signo está sujeito a critérios de avaliação ideológica, pois tudo que é ideológico possui valor semiótico e o campo dos signos coincide com os campos da ideologia. Nas imagens, por exemplo, é possível adicionar significados positivos ou negativos de acordo com as construções semióticas (Kress \& Van Leeuwen, 2006) com potencial de transmitir posicionamentos avaliativos ao que está representado (Machin, 2007). Seja através da distância da pessoa representada, seja pela escolha das cores, das sombras, das luzes, do foco, do tamanho e com uma produção que traz ou não caráter de realidade (Kress e Van Leeuwen, 2006; Machin, 2007). Sendo assim esses materiais semióticos fotográficos são capazes de moldar a organização e as interações sociais (Ledin \& Machin, 2018).

Erving Goffman (2013) afirmou que as pessoas são atores sociais, ou seja, representam papéis sociais que os colocam em lugares definidos pela sociedade. E é nessa demarcação de espaços que residem as forças para a manutenção de certas ordens 
sociais e simbólicas como a estereotipização e a criação dos mitos. Para Hall (1997) estereotipar estabelece uma fronteira entre o normal e o desviante, o que pertence e o que não pertence, o "nós" e o "eles". Dessa forma reduz, naturaliza e conserta as diferenças, excluindo ou expelindo tudo aquilo que não se enquadra. Os estereótipos são uma forma de classificação que contêm uma atitude negativa frente a certos grupos sociais (Guimarães, 1999, p. 9) sendo eficaz para marginalizar e excluir minorias (Van Dijk, 2015). Com efeito, Biroli (2010) afirma que os estereótipos de gênero presentes na mídia devem ser entendidos como produtos de uma ampla dinâmica social, que envolve a determinação de papéis diferenciados, e hierarquicamente distintos, para homens e mulheres.

Para Scott (1988) o termo gênero tem conotação política e serve como instrumento no legitimar das lutas feministas, na produção de conhecimento, mas também na esfera social. Para ela, gênero se percebe através das diferenças e é o modo primeiro de significar relações de poder (Scott, 1995). Quanto à marcação social das diferenças, se faz importante perguntar quais são as representações simbólicas evocadas, em quais contextos e de que forma. A autora, através da noção de fixidade, aborda a ideia de uma representação binária eterna dos gêneros, com a necessidade de incluir a noção do político às análises dos discursos (Scott, 1988). Ao tratar da identidade subjetiva, aborda conceitos de poder e da distribuição do capital através do acesso ou não a estes recursos simbólicos e materiais, demonstrando que o gênero está implicado na construção e na concepção do poder em si (Scott, 1995). Esse poder sustenta o patriarcado enquanto posição de superioridade masculina e dos homens enquanto categoria social. O patriarcado organiza as relações regido por um princípio rígido de que mulheres são subordinadas hierarquicamente aos homens (Narvaz \& Koller, 2006). Entendemos que a imagem da mulher através da mídia e, em especial, das fotografias é um discurso social criado pelo patriarcado e sustentado através da reprodução de consensos e de imagens mentais que fomentam e mantêm estereótipos de gênero.

De acordo com Young (2006), uma característica da hegemonia masculina na política e nos espaços públicos reside no fato de ela não ser reconhecida enquanto tal. Neste sentido, "onde certos grupos sociais estruturais lograram dominar as discussões e as decisões políticas, suas perspectivas sociais geralmente definem as prioridades políticas, os termos nos quais elas são discutidas e a noção de relações sociais que enquadra a discussão" (Young, 2006, p. 174). Young acrescenta ainda que "essas perspectivas frequentemente não são reconhecidas como um modo específico de olhar as questões em pauta, mas tomadas como neutras e universais" (2006, p. 174). A pesquisa Global 
Uma mulher no espaço político: Um estudo comparativo entre as representações

fotográficas de Dilma Roussef e Aécio Neves na mídia tradicional brasileira

Media Monitoring Project, por exemplo, demonstrou essa invisibilidade feminina na mídia quanto aos assuntos políticos: "estudos conduzidos em vários países demonstram que, também na política, as mulheres alcançam menor visibilidade midiática" (Martins, 2015, p. 75). A importância de pesquisas assim se deve ao fato de que é preciso conhecer a realidade para contestá-la, sendo essa uma base da crítica feminista das representações (Mota Ribeiro, 2005). Uma das propostas feministas, para além de desmistificar a genderização dos discursos é tornar possível uma nova forma de representação e ocupar os espaços de liderança através do feminismo, pois a "luta das mulheres pela garantia dos direitos, entre os quais os políticos, é indissociável dos movimentos feministas" (Martins, 2015, p. 20). Os estereótipos constituem um aliado da distribuição desigual de justiça pelos indivíduos na sociedade (Simões, 2017, p. 6) e, por isso, devem ser vistos enquanto fontes de manutenção do poder social masculino.

Sobre representações estereotipadas de mulheres políticas, a pesquisa de Bulawka (2012) sobre a imprensa da Polônia demonstrou que a representação midiática destas estava na maioria das vezes vinculada à tipos identitários típicos do senso comum sobre comportamentos vistos como femininos. A maioria do material analisado trazia ligação com arquétipos como o de mãe, o de bruxa, o de sedutora ou o de princesa. Uma pesquisa semelhante realizada sobre a imprensa inglesa (Baxter, 2017) mostrou que as líderes femininas foram frequentemente transformadas em símbolos de organizações cuja dominação era masculina, geralmente em papéis amordaçados como os maternos, os sedutores ou os de mulheres de ferro. As conclusões de pesquisas como estas apontam para uma produção de efeitos avaliativos negativos relacionados às mulheres em posições de poder a partir de textos e de imagens, de forma que as interpretações sociais destes materiais levem o público a conclusões sexistas e anti transformadoras.

Como as imagens são visões do mundo (Rose, 2001) construídas socialmente, interrogar o modo como tornam visíveis ou invisíveis as diferenças é fundamental. A necessidade das análises comparativas das representações fotográficas de políticos homens e mulheres reporta-se ao fato de as relações criadas através dos discursos das fotografias não serem neutras ou impensadas, mas sim uma parte de um contexto social onde a estrutura societária patriarcal molda o padrão de construção discursiva. A mensagem de que mulheres não estão aptas para cargos de liderança e cargos políticos usa dessas ferramentas para abalar a credibilidade intelectual e emocional do feminino. É neste contexto que Dilma se torna um símbolo.

Uma análise semiótica investiga "os modos de dizer, os modos de mostrar e/ou os modos de seduzir; detecta traços recorrentes invariantes de operações de enunciação 
a partir das marcas que essas operações deixam na superfície textual, no verbal e no não verbal, e os organiza sob a forma de regras" (Pinto, 1995, p. 147). Na perspectiva estruturalista de Barthes (1956), as imagens que interagem criam um sistema de significados que repete a estrutura da linguagem e reflete as funções sociais da mitologia. Essas imagens são capazes, inclusive, de atribuir a um indivíduo aspectos de representação de caráter da feição ideal de um cargo, ou nas palavras de Barthes, a fotogenia eleitoral (1956). Justamente por produzir a ideia de realidade os materiais fotográficos são ideologicamente potentes ao não apenas registrar um momento, mas sim promover afetos ao transmitir "tipos particulares de scripts, valores e identidades" (Machin, 2004, p. 781).

Montezano e Pimenta (2016) defendem que a semiótica é "uma ciência que se propõe estudar todas as formas de comunicação. Ela trata tudo que está ao nosso redor como signos, e busca apreender o máximo da totalidade de percepções e interpretações, que se pode haver sobre eles" (p. 6). Nesta mesma linha de raciocínio, Santaella (2002) argumenta que um signo representa algo e, para além disso, é capaz de produzir efeitos de interpretação em mentes reais ou potenciais. A mídia muitas vezes se utiliza destes efeitos para produzir, através das imagens, novas interpretações dentro das notícias. Como sustentou Guy Debord (1931), “o espetáculo não é um conjunto de imagens, mas uma relação social entre pessoas, mediada por imagens (...) e como, se é tão óbvio, se torna invisível” (p. 301). E os problemas éticos surgem justamente devido a esta invisibilidade, pois dela decorre uma "violência suave, insensível, invisível a suas próprias vítimas, que se exerce essencialmente pelas vias puramente simbólicas da comunicação e do conhecimento, ou, mais precisamente, do desconhecimento, do reconhecimento ou, em última instância, do sentimento" (Bourdieu, 1998, p. 22-23).

De acordo com Kossoy (1999), a fotografia sempre esteve à disposição das ideologias, prestando-se aos mais diferentes usos. Sendo assim, "as imagens técnicas tornam as imagens mentais reais. As fantasias da imaginação individual e do imaginário coletivo adquirem contornos nítidos e formas concretas através do testemunho fotográfico" (Kossoy, 1999, p. 140). O poder de produzir e fortalecer estereótipos a partir de conteúdos fotográficos se deve a capacidade de emocionar mais do que o discurso escrito e de uma maior possibilidade de perdurar, pois no caso das fotografias as repetições de discurso se tornam menos óbvias. Ao serem repetidos vezes suficientes, os estereótipos visuais tornam-se parte de uma cultura (Lester, 1995, p. 104).

Para a autora Ana Maria Mauad uma imagem "não fala por si só; é necessário que as perguntas sejam feitas" (Mauad, 1996, p. 83). Considerando o grande poder 
Uma mulher no espaço político: Um estudo comparativo entre as representações

fotográficas de Dilma Roussef e Aécio Neves na mídia tradicional brasileira

político das imagens e a sua produção de afetos, um olhar crítico sobre esses materiais torna-se fundamental para a área de estudos de comunicação. Neste sentido, neste artigo propomos analisar de que forma as narrativas sobre gênero expressas nas representações fotográficas de Dilma Roussef e de Aécio Neves publicadas pela revista IstoÉ contribuíram para a construção de suas imagens políticas e quais foram as estratégias semióticas utilizadas nas fotografias selecionadas pela publicação para ambos. Através de uma análise semiótica comparativa buscamos captar quais os afetos suscitados pelas fotografias e vinculados ao senso comum sobre mulheres e homens na política e nos espaços públicos de poder.

\section{METODOLOGIA}

A comunicação visual não pode ser vista fora dos contextos sociais e, por isso, uma fotografia, por exemplo, não é apenas uma imagem, mas sim um universo de significados construídos (Ledin \& Machin, 2018). Por essa razão as pesquisas sobre materiais fotográficos não costumam abordar apenas a materialidade, mas as experiências, intenções, contextos e formas de exploração da imagem. Materiais semióticos estruturam a maneira como interagimos ao entregar valores não consensuais através de discursos repetitivos (Ledin \& Machin, 2018).

Neste artigo analisamos as escolhas fotográficas de IstoÉ para representar Dilma Roussef e Aécio Neves, ambos candidatos nas eleições presidenciais no Brasil em 2014. Utilizamos a Análise Crítica do Discurso (ACD) por ser uma metodologia que nega o conceito de neutralidade científica. Entendemos que a mídia e suas imagens interferem na construção do imaginário popular e do senso comum. Para Butler (2015) o simples ato de enquadrar já não é neutro, pois as delimitações de espaço já são operações de poder e, por isso, reproduzidas intencionalmente. Enquadrar rouba a interpretação do todo, direciona interpretações de forma implícita e produz efeitos fracionados. As fotografias aqui analisadas são, então, materiais de interpretação, ou seja, lugares próprios da ideologia materializados pela História (Orlandi, 1996).

A ACD aborda o estudo das linguagens na sociedade e se distingue de outras abordagens pela sua característica multidisciplinar, ao ter um diálogo direto com outras ciências sociais. Para Norman Fairclough (2003) a ACD provê bases científicas para questionamentos da vida social com relação ao poder, aos termos políticos e morais e à justiça social. Ou seja, suas análises tem o objetivo geral de desvelar situações de 
poder e desconstruir interpretações implícitas nos discursos. Por essas razões, a ACD é uma abordagem teórico metodológica com objetivos emancipatórios (Fairclough, 2000) amplamente utilizada, por exemplo, nas análises sociais sobre raça e gênero. As metodologias deste campo representam "uma tomada de posição que se quer crítica quanto aos sentidos já constituídos e dados como óbvios" (Mariani, 1996, p. 25). Por essa razão, a escolha desta metodologia teórica para análises referentes às representações femininas conversa intimamente com os pressupostos da teoria feminista, que também nega a neutralidade tanto dos geradores dos discursos, como dos analistas. Utilizamos as categorias de análise definidas por David Machin e Andrea Mayr no livro How to do Critical Discourse Analysis (Machin \& Mayr, 2012) que, inspirados em Kress \& Van Leeuwen (2006) e nos marcadores de modalidade visual, apresentaram ferramentas para descrever os níveis e tipos de elementos presente nas imagens. Esse método de análise semiótica fotográfica permitiu aferir, para além dos padrões e das repetições, significados sociais mais aprofundados e de que forma essas ideias foram moldadas pela ideologia dominante (Ledin \& Machin, 2018). Para além da metodologia da ACD, nos pautamos na perspectiva Barthiana em termos estruturais dos processos de conotação, nomeadamente trucagem, pose, objetos e fotogenia. Para isso, utilizamos a proposta de Pacheco (2008):

“Trucagem são os processos de alteração do conteúdo da fotografia através de técnicas artificiais que alteram o conteúdo do que foi originalmente fotografado, como a montagem, por exemplo, que pode mudar totalmente o sentido uma mensagem fotográfica. A pose é o processo pelo qual o fotógrafo lança mão de elementos iconográficos que estão presentes numa gramática histórica presente nas artes (pintura, teatro, escultura), nas associações de idéias, nas metáforas concorrentes, etc. Os objetos que aparecerão na fotografia são previamente selecionados pelo fotógrafo com a intenção de elaborar a sua mensagem fotográfica, de modo ser compreendida pelo público-alvo, mas não só a seleção do objeto, mas também como ele será fotografado. A fotogenia que já foi objeto de estudo de Edgar Morin em Le cinema e l'homme imaginaire, pode ser explicada em termos de estrutura comunicativa, que a mensagem conotada reside na própria imagem embelezada quando o propósito é qualificar, e enfeada quando o propósito é desqualificar, este controle se dá por técnicas de iluminação, angulação, maquiagem e impressão" (p. 4). 
Uma mulher no espaço político: Um estudo comparativo entre as representações

fotográficas de Dilma Roussef e Aécio Neves na mídia tradicional brasileira

O primeiro passo da análise foi a descrição das fotos analisadas, seguido das suas interpretações que consideram o contexto em que se inscreveu, pois as imagens possuem "sem dúvidas, um caráter conotativo que remete às formas de ser e agir do contexto no qual estão inseridas as imagens como mensagens" (Cardoso \& Mauad, 1997, p. 466). Importante ressaltar o respeito às dificuldades desta tarefa, pois "a descrição de uma fotografia é literalmente impossível; porque descrever consiste exatamente em juntar à mensagem denotada um relê ou uma mensagem segunda, mergulhada em um código que é a língua" (Barthes, 1982, p. 328).

O corpus de análise foram seis fotografias publicadas pela IstoÉ, sendo duas imagens de capas da revista e quatro imagens de reportagem publicadas nas edições 2268, 2337 e 2417, dos meses de maio de 2013, setembro de 2014 e abril de 2016 respectivamente.

IstoÉ é uma revista do Brasil criada em 1976 e atualmente publicada aos sábados. Ela tinha inicialmente uma periodicidade mensal e em março de 1977 passou a circular semanalmente. Na apresentação que Mino Carta, o primeiro diretor da IstoÉ, fez da revista, em seu primeiro número, afirmou que em suas páginas "cada um escreve com franqueza e com as suas próprias palavras, sendo que uma harmoniosa desunião serviria como prova, entre outras, de amor pela tolerância, pelo diálogo, pela democracia" (Naldoni, 2012). Durante a fase em que circulou mensalmente, IstoÉ priorizou a publicação de grandes reportagens e matérias de análise.

Em 2013, a circulação de IstoÉ era de cerca de 405.000 cópias por mês. Atualmente sua auditoria de circulação não é publicada. Ela é considerada nas três principais revistas publicadas no país, além da Veja e Época. A revista IstoÉ se define como independente e nunca vinculada a grupos políticos ou económicos. Foi a primeira revista brasileira a publicar integralmente seus conteúdos online ao criar o site IstoÉ Online.

Dilma Rousseff é uma economista e política e a primeira mulher na presidência brasileira (e a 36 ${ }^{\mathrm{a}}$ presidenta), ocupando o cargo de 2011 a 2016. Anteriormente, atuou como Chefe de Gabinete do ex-presidente Luiz Inácio Lula da Silva de 2005 a 2010. Filha de imigrante búlgara, Dilma foi criada numa família de classe média em Belo Horizonte. Após o golpe de estado de 1964, ela juntou-se a um grupo de esquerda que lutou contra a ditadura militar. Dilma foi capturada, torturada e presa de 1970 a 1972, com menos de 20 anos de idade.

Aécio é um político e ex-presidente do Partido da Social Democracia Brasileira (PSDB). Ele foi o governador mais jovem de Minas Gerais (de 2003 a 2010) e é membro da Câmara dos Deputados. Aécio é filho do político Aécio Cunha e de Inês 
Maria. Neves vêm de uma família de políticos tradicionais de Minas Gerais. Iniciou a sua carreira política como secretário pessoal do seu avô, Tancredo Neves, eleito presidente do Brasil em 1985, que morreu antes de assumir o cargo. Ele perdeu a eleição presidencial contra Dilma em 2014.

Com o conhecimento que "as questões de gênero, a misoginia, o sexismo, a herança de uma cultura que se forjou no patriarcado, foram ingredientes apontados como de grande relevância para influenciar a opinião pública durante a cobertura do processo de impeachment" (Geraldes et al., 2016, p.10), este artigo busca demonstrar que as escolhas das imagens e das palavras não são imparciais, mas antes reforçam papéis de gênero. Como explica Braidotti (1991), as pesquisas utilizam a linguagem do homem. Por isso, neste trabalho escolhemos a palavra presidenta, que do ponto de vista formal é correta e tem um papel político, reafirmando o gênero da primeira mulher a ser eleita presidente do Brasil.

\section{UM ESTUDO COMPARATIVO ENTRE AS REPRESENTAÇÕES FOTOGRÁFICAS DE DILMA ROUSSEF E AÉCIO NEVES NA REVISTA ISTOÉ}

\section{Figura 1}

Imagem da reportagem "Uma presidente fora de si" (Pardellas, 2016) publicada em seis de abril de 2016

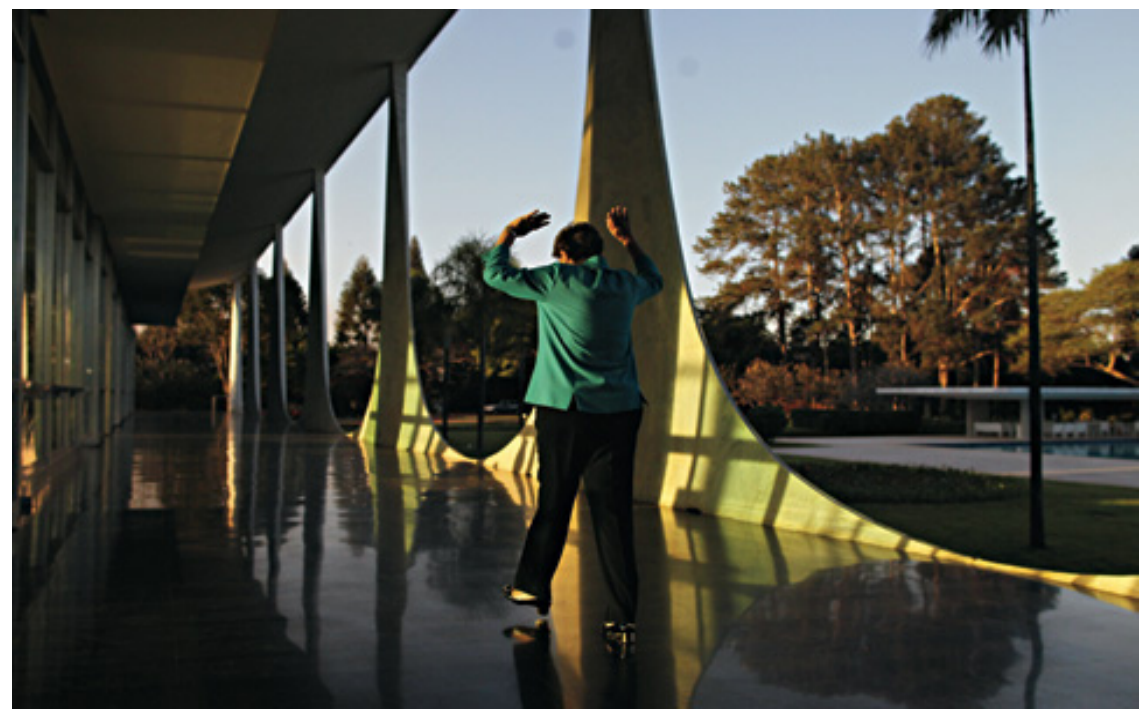

Fonte: IstoÉ 
Uma mulher no espaço político: Um estudo comparativo entre as representações fotográficas de Dilma Roussef e Aécio Neves na mídia tradicional brasileira

Na reportagem "Uma presidente fora de si" publicada em seis de abril de 2016 temos a imagem de Dilma (Figura 1) com os braços para cima de costas e caminhando na direção contrária ao fotógrafo por um corredor externo do Palácio Presidencial. A foto não é posada, no sentido em que foi captada num momento espontâneo, as sombras estão bem marcadas e ela aparece sozinha. Lemos abaixo da imagem a seguinte legenda "Descontrole: a presidente se entope de calmantes desde a eclosão da crise. Os medicamentos nem sempre surtem efeito, atestam os seus auxiliares" (Pardellas, 2016, s/p). Assim como na vida real, a distância entre pessoas dá significado às relações sociais (Machin \& Mayr, 2012, p. 103). A aproximação fotográfica, por exemplo, é capaz de transmitir ao observador os sentimentos e os estados psicológicos dos retratados. Esta escolha por um distanciamento longo não conota intimidade, mas solidão e isolamento (Machin \& Mayr, 2012, p. 103). Esta criação semiótica é extremamente refinada e combina com a intenção de provocar a ideia de imparcialidade dos autores, ao mesmo tempo em que claramente remete a ideia de não pertencimento de Dilma nos cenários políticos de poder. Todas estas características levam as seguintes interpretações: Dilma está sozinha, sem apoio. Pode ser apontado também nesta imagem um contraste plástico, que segundo Oliveira (2004), "se define como a co-presença na mesma superfície dos termos opostos" (p. 90-91), neste caso o Palácio do Planalto e Dilma. Na imagem Dilma não parece pertencer ao Palácio, visto aqui como um símbolo de local político. Os locais políticos são marcados pela "grandeza ou a ostentação, a decoração ou o fausto, o cerimonial ou protocolo" (Balandier, 1982, p. 10). Dilma não possui qualidades para pertencer a este espaço. Também há a presença da perspectiva de que mulheres são vazias de história e propensas ao descontrole emocional (Beauvoir, 1960). Na imagem, Dilma é retratada como não querendo diálogo, estando sem controle e a racionalidade necessária a um governante, inferindo-se que ela não está pronta para o Palácio do Planalto e para as suas funções. 


\section{Figura 2}

Imagem da reportagem "Uma presidente fora de si" (Pardellas, 2016) publicada em seis de abril de 2016

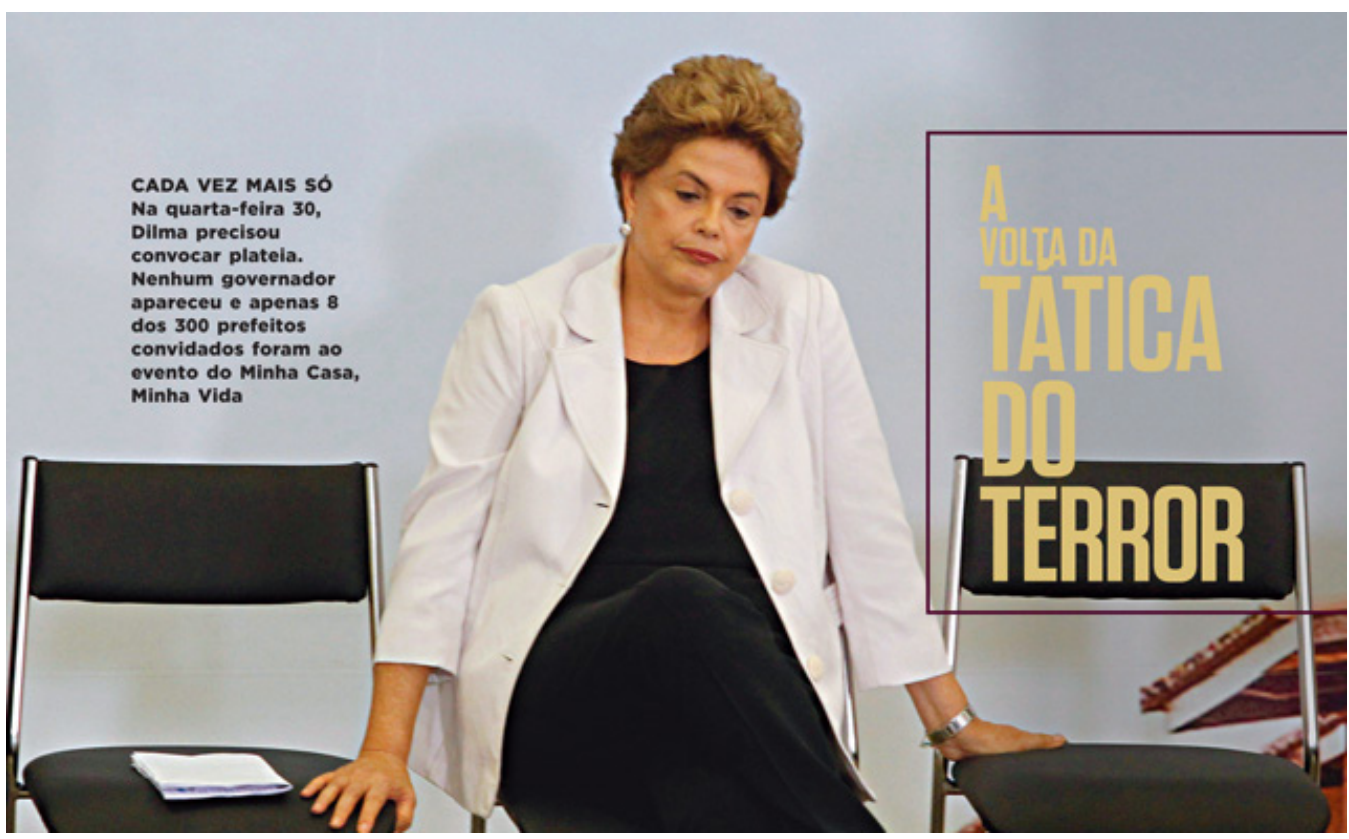

Fonte: IstoÉ

Na Figura 2 Dilma está no centro da imagem, sentada entre duas cadeiras vazias, onde ela apoia as duas mãos, uma em cada cadeira. Ela está abatida, cabisbaixa, e numa foto espontânea, não posada. As palavras dentro da imagem dizem "A volta da tática do terror". O olhar é um ponto de análise fundamental da relação entre o observador e a pessoa retratada e pode guiar para discursos não explícitos (Machin \& Mayr, 2012, p. 100). O olhar é um recurso semiótico usado para provocar interesse e engajamento (Machin \& Mayr, 2012). Para Kress e Van Leeuwen (2006) uma imagem pode ser de oferta ou de demanda, dependendo da ação ou da interação com a pessoa retratada. Quando o retratado olha para a câmera isso cria uma imagem de demanda, pois o cruzamento dos olhares cria uma relação imaginária com o observador, uma relação social imaginária (Kress \& Van Leeuwen, 2006, p. 124). Assim, imagens de demanda colocam o fotografado enquanto protagonistas de uma ação e o observador enquanto participante desta. Já as imagens de oferta conferem ao retratado a passi- 
Uma mulher no espaço político: Um estudo comparativo entre as representações

fotográficas de Dilma Roussef e Aécio Neves na mídia tradicional brasileira

vidade de serem observados e auxiliam na criação de um ambiente de julgamento. Os observadores foram convidados a observar Dilma e a avaliar sua personalidade, enquanto representante política de forma negativa, dado que seu olhar quase sempre vago ou voltado para baixo indica pensamentos negativos e submissão (Machin \& Mayr, 2012). O olhar voltado para baixo contido na imagem avaliada pode também remeter ao estereótipo de gênero das figuras femininas religiosas, muito utilizadas como exemplos de mulher na educação das meninas (Flores, 2012), de forma que sinalizam uma espera pelo silêncio público de Dilma nos espaços de poder.

Sobre os outros componentes da fotografia, para Ana Maria Mauad (2007), no campo da análise semiótica "os objetos presentes na fotografia devem ser analisados a partir da função sígnica que assumem na dinâmica da representação” (p. 135). Nesse caso, a presença das cadeiras na imagem cria uma nova característica interpretativa sobre Dilma. A sua roupa tem a mesma cor das cadeiras, de forma a transformá-la em mero objeto, sem apoio humano (por isso não tem onde posicionar as mãos) e totalmente isolada. Para a historiadora Miria M. Leite (1993), a escolha da noção de espaço na leitura das mensagens visuais se faz fundamental, pois "a fotografia é uma redução, um arranjo cultural e ideológico do espaço geográfico, num determinado instante" (p. 19), acrescenta-se ainda a questão de que a forma como os elementos estão dispostos em uma cena criam uma relação direta com o espectador (Fresnaultderuelle, 1993).

Sobre o uso de fotografias onde Dilma aparece sozinha, vale ressaltar estudos que mostram o papel de líderes ou parceiros políticos na trajetória individual e como homens e mulheres enxergam ou são levados a enxergar a sua posição com relação aos parceiros e linhagem política e essa descendência. Ao entrevistar deputadas e deputados federais para a sua pesquisa, Araújo (2010) verifica que a influência do líder é mais marcante no discurso das mulheres, enquanto os homens não assumem claramente essa relação de patronagem, preferindo narrar a sua atuação política como projeto pessoal autônomo. Isso fica nítido na ênfase fotográfica que tem a solidão de Dilma, e na forma como as imagens de Aécio sozinho tomam um caráter de autonomia e independência, conforme veremos a seguir, na próxima análise.

O que está implícito nas imagens escolhidas para a reportagem sobre Dilma seria de que o poder, quando colocado nas mãos de uma mulher, deve ser expresso com traços de ternura, ou será julgado como manifestação violenta e desequilibrada. É possível associar isto ainda ao que Landowski (2012) chamou de "negação do outro" (p. 33) que para ele é a tendência de negar a alteridade dos que são diferentes. As 
mulheres são, assim, colocadas como inferiores e não preparadas para executarem cargos públicos e políticos. Isso remete ao ideal patriarcal do encarceramento das mulheres no âmbito privado:

Por toda a parte, as atividades valorizadas são as exercidas pelos homens; por toda parte, os mitos e discursos evocam a natureza inferior das mulheres; por toda parte, o masculino é designado por valores positivos e o feminino, por valores negativos; por toda parte se exerce a supremacia do sexo masculino sobre o sexo feminino (Lipovetsky, 2000, p. 232).

\section{Figura 3}

Imagem da reportagem "Temos um país à deriva em busca de um gestor" (Simas Filho, 2013). Publicada em oito de maio de 2013

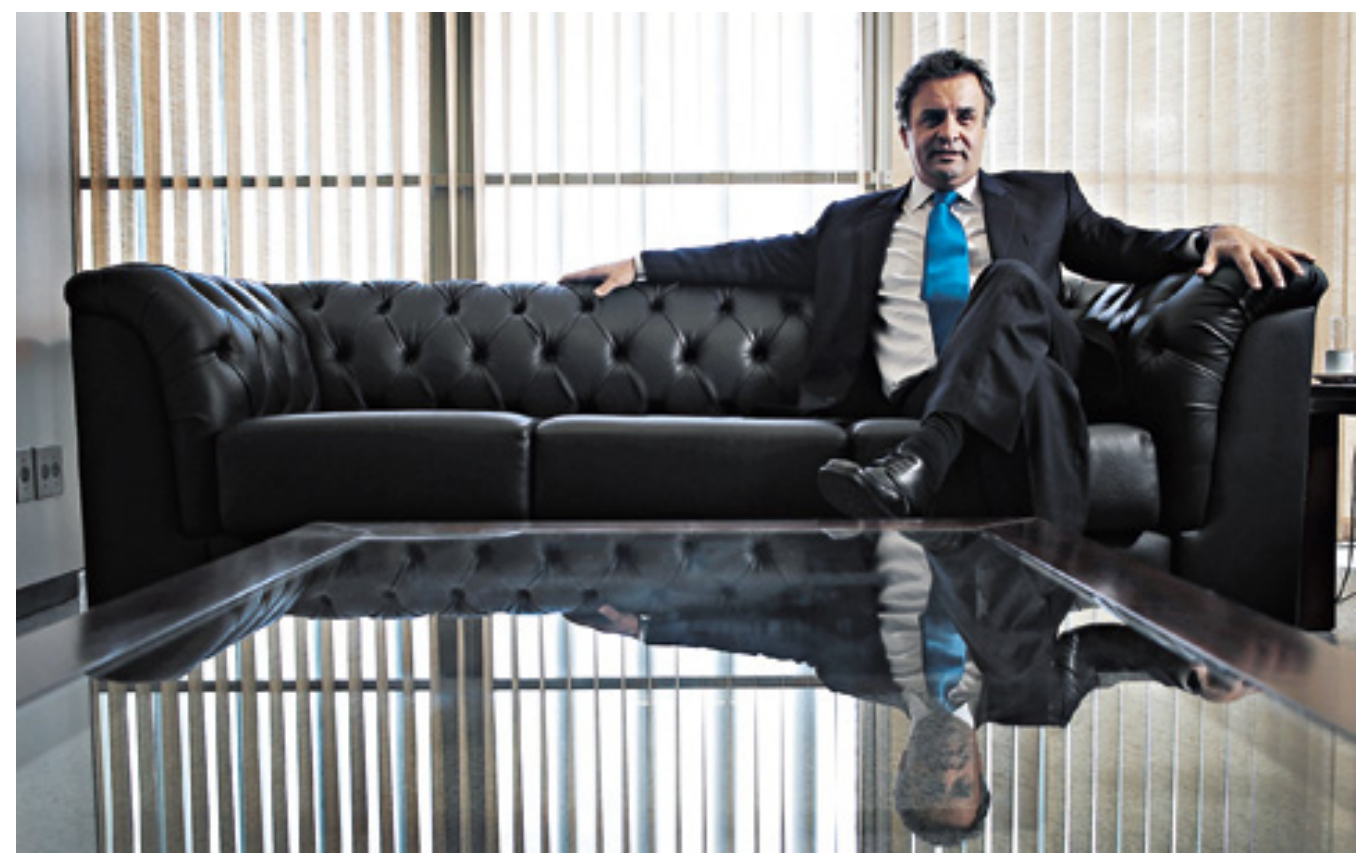

Fonte: IstoÉ

Considerando a reportagem intitulada "Temos um país à deriva em busca de um gestor" publicada em três de maio de 2013 e referente ao candidato presidencial Aécio Neves, 
Uma mulher no espaço político: Um estudo comparativo entre as representações fotográficas de Dilma Roussef e Aécio Neves na mídia tradicional brasileira

as imagens escolhidas são um conjunto de quatro fotografias não espontâneas, planejadas, executadas e editadas. Quanto à fotogenia, aferiu-se que em todas elas a ideia foi embelezar para qualificar. O ambiente é profissional, e com tons neutros, ressaltando a gravata azul de Aécio, cor símbolo do seu partido. Na Figura 3, o candidato aparece sentado com os braços abertos num sofá, e com as pernas cruzadas. A pose é fundamental para a análise, pois marca "usualmente o protocolo de base da atitude pelo qual o retratado se colocava para a fixação da sua imagem: era mediante tal gênero de disposição que os modelos se dispunham a exibir os traços pelos quais supunham dever ser reconhecidos" (Picado, 2009, p. 7). O reflexo da pose aparece na mesa de vidro, que toma na imagem a função de espelho, pois se trata de um político transparente. Esse reflexo, e a ideia inconsciente de transparência, constroem o fenômeno da identificação social deste sujeito (Gombrich, 1984).

\section{Figura 4}

Imagem da reportagem "Temos um país à deriva em busca de um gestor" (Simas Filho, 2013). Publicada em oito de maio de 2013

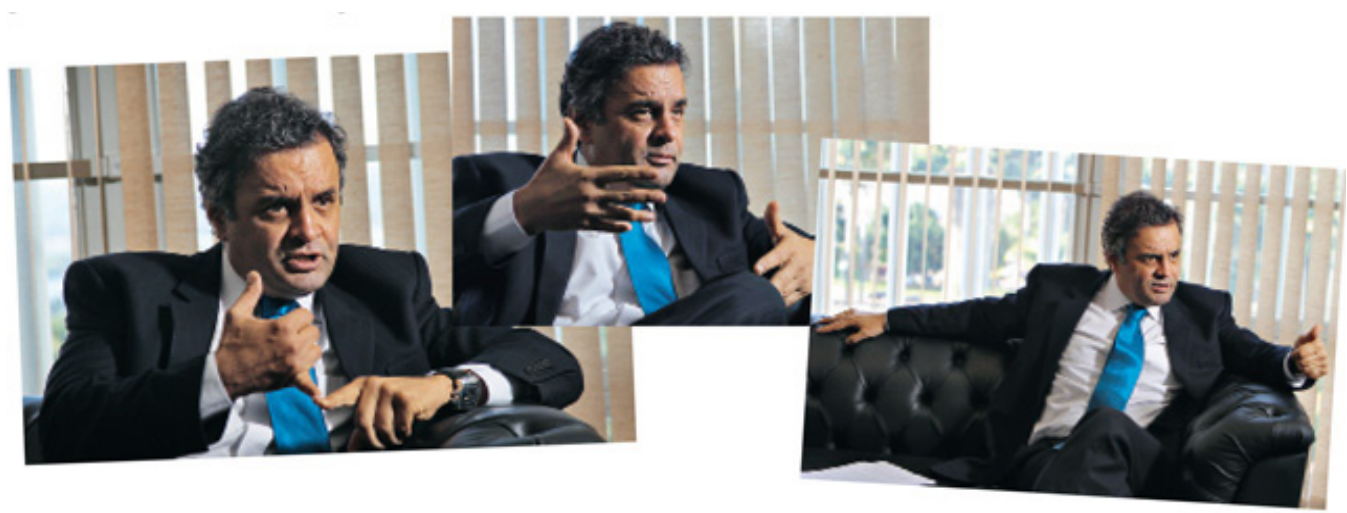

Fonte: IstoÉ

A Figura 4 consiste numa montagem de três fotos de Aécio durante a entrevista realizada no âmbito da reportagem "Temos um país à deriva em busca de um gestor". Nestas imagens, o candidato gesticula com as mãos e tem o olhar confiante. As interpretações são de que Aécio, como homem, é autor da sua trajetória. Ao contrário de Dilma, o candidato foi ouvido e pode pensar sobre a sua própria representação levando em conta que "o ethos político se deixa gravar, de certo modo, nos aspectos através dos quais a apresentação do indivíduo na imagem é, de alguma maneira, gestada" 
(Picado, 2009, pg. 7). Aécio é gestor, pertence à política e a sua roupa combina com a daquele ambiente. A sua imagem masculina na política é tida como natural, forte e correta. Esse seria o espaço que um homem deve e pode ocupar e por isso as imagens políticas masculinas costumam ser retratadas com padrões de embelezamento:

Outra característica da mensagem transmitida é o sentido de estabilidade e equilíbrio dado pela combinação retangular/horizontal/central, enfatizada também pela combinação entre objeto central no primeiro plano, concentração na parte superior da foto, foto posada, permitindo a profundidade de campo, e controle da encenação através da pose (Mauad, 2007, p. 127).

Todas estas características da imagem nos trazem um sentido de "ordenação e hierarquização, próprio ao grupo que tinha como projeto a direção da sociedade" (Mauad, 2007, p. 127). O conjunto de imagens leva à conclusão de que a figura política do homem Aécio Neves é forte, transparente, preparado e sólido no que Lipovetsky (1981) chamou de império das aparências.

\section{Figura 5}

Capa da edição 2337

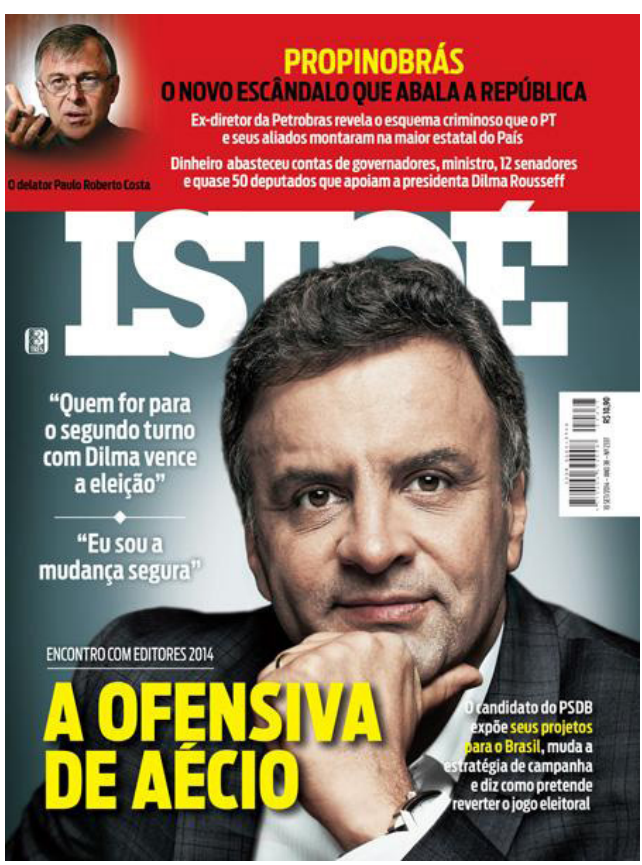

Fonte: IstoÉ

\section{Figura 6}

Capa da edição 2417

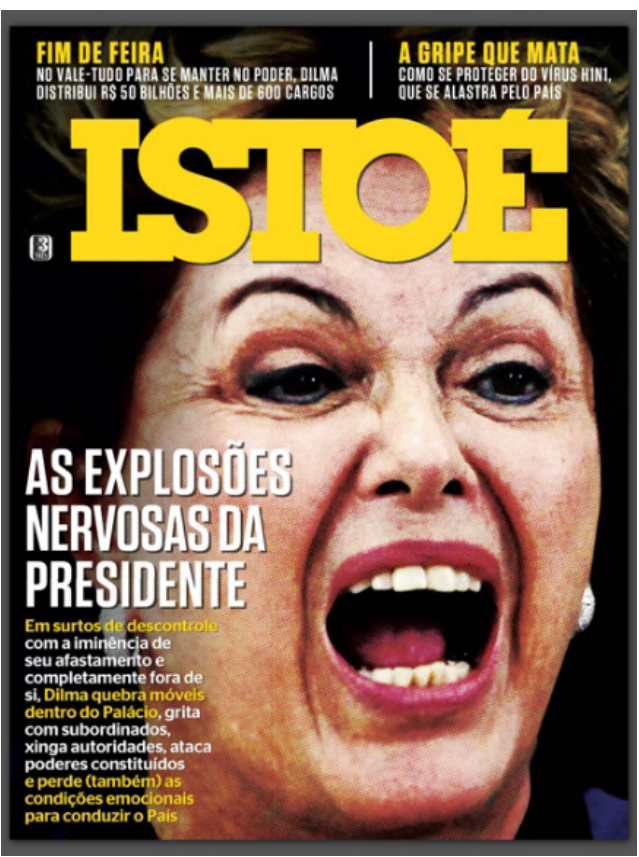


Uma mulher no espaço político: Um estudo comparativo entre as representações

fotográficas de Dilma Roussef e Aécio Neves na mídia tradicional brasileira

A oposição fotográfica das duas imagens de capa de cada reportagem merece destaque nesta análise. Na Figura 5 é realçada a fotogenia de Aécio Neves, com uma função clara de embelezar enquanto retrato, considerando que "representar alguém é atribuir-lhe distinção" (Picado, 2009, p.7). Na Figura 6 verifica-se o oposto com a imagem de Dilma. Com recurso a edição, a imagem da candidata mostra as suas rugas marcadas e a cor da sua pele modificada. estratégias semióticas de uso de cores que visam o distanciamento da pessoa retratada com a realidade, através do uso de cores não naturais, que tem o poder de reduzir a forma como as coisas aparecem no cenário real (Machin \& Mayr, 2012). Além disso, as sombras marcadas criam significados de emoção extrema ou de melancolia (Machin \& Mayr, 2012). Considerando o elemento pose, verifica-se que a de Aécio tem forte relação com a escultura Le Penseur (O Pensador) do francês Auguste Rodin, que remete a características da razão, além do punho fechado como símbolo de força e de alguém que está pronto para a luta, numa clara concordância com as palavras "A Ofensiva de Aécio" (Marques, 2014), destacadas na cor amarela. Esse conjunto traz para a Figura 5 os conceitos de Greimas e Courtés (1979,) da "performance ou saber fazer" (p. 328) e também da euforia. Nesta representação, Aécio surge como um herói. A Figura 6 traz recursos de trucagem, pois a fotografia de Dilma foi manipulada e retirada de contexto. Na fotografia original, Dilma comemorava um gol no Brasil na Copa do Mundo de Futebol, e a retirada contextual foi usada na capa da revista como um colapso nervoso. Um caso claro de fraude na mídia e distorção de fatos reais. A este propósito, referimos que o conteúdo da reportagem trouxe alegações de que a presidente estava fazendo uso de dois medicamentos para os ataques de raiva e esquizofrenia. Com um relatório demonstrando que as notícias sobre a doença e as drogas eram falsas, Dilma venceu a ação contra a revista IstoÉ (processo 2016.01.1.048516-3) com a decisão da juíza Tatiana Dias da Silva, do 18 Tribunal Civil de Brasília. A alteração do conteúdo na imagem através da retirada do contexto e da mudança do sentido fotográfico traz claros traços de trucagem.

A fotografia de capa em "As explosões nervosas da presidente" e as outras imagens desta reportagem trazem o estereótipo da mulher fora de si, historicamente utilizado para desvalorizar o feminino. O termo em inglês gaslighting se refere a uma violência emocional onde, por meio da manipulação, uma mulher, dentro de um contexto, acredita estar fora de si ou louca e duvida de si mesma. De acordo com Barthes (1982), a fotografia e a imagem não são estruturas isoladas do mundo, mas sim se comunicam "pelo menos com uma outra estrutura, que é o texto (título, legenda ou 
artigo) de que vai acompanhada a foto impressa" (p. 326). No conteúdo da matéria, expressões como "perdeu as estribeiras", "os nervos estão à flor da pele" e "mais agressiva do que nunca" trazem o contraponto de a raiva não ser permitida a mulheres, que são socialmente educadas para serem amáveis, passivas e estáveis.

Finamore e Carvalho (2006) consideram que as questões de gênero medeiam as representações de candidatos a cargos públicos e a mídia associa as candidatas aos estereótipos do senso comum. Já os homens não recebem essa ênfase de preconceitos: "isso sinaliza a presença de um discurso masculino sobre as mulheres que vem sendo construído e mantido, enquanto os homens são muitas vezes preservados de marcas discriminatórias" (Finamore e Carvalho, 2006, p. 353). Por essa razão Dilma foi descrita em termos de vida pessoal, de personalidade, de aparência muito mais do que no campo dos ideais políticos pois "a vida privada/familiar e o trato social são enfatizados no caso feminino, em conformidade com as expectativas de polidez e cuidado das relações sociais generificadas; ao passo que habilidade técnica e firmeza são as qualidades masculinas tipicamente destacadas" (Carniel, Ruggi, \& Ruggi, 2018, p. 12).

\section{CONCLUSÃO}

O objetivo deste artigo foi analisar as representações fotográficas de Dilma, num comparativo com as de Aécio Neves nas reportagens da IstoÉ. A análise permite inferir marcas deixadas repetidamente nos discursos que revelam Aécio de maneira positiva e Dilma de maneira negativa, dando pistas do tratamento desigual recebido por ambos por parte da mídia tradicional brasileira.

Todos os materiais fotográficos são ideológicos e servem a interesses sociais particulares (Ledin \& Machin, 2018) e o processo de produção, de enquadramento, seus recortes ou a ausência de percepção da historicidade podem silenciar possíveis sentidos ou dar a falsa impressão de neutralidade às fotografias. Através do efeito de verdade que a comunicação visual produz, os sentidos sociais são sedimentados no senso comum, produzindo interpretações ligadas a memórias discursivas (Flores, 2017). Não somente a materialidade importa, mas a experiência dos observadores, as intenções, os contextos e as formas de exploração das ideias (Ledin \& Machin, 2018).

Identificar de que forma as mulheres são representadas e socialmente construídas é um passo fundamental para a emancipação, dado que o que é construído pode 
Uma mulher no espaço político: Um estudo comparativo entre as representações

fotográficas de Dilma Roussef e Aécio Neves na mídia tradicional brasileira

ser modificado. O uso dos recursos metodológico da ACD pode fornecer subsídios para construções científicas críticas posicionadas contra a hegemonia masculina nos espaços públicos de poder. Por isso a importância de análises cujos recortes desvelem situações de poder.

A partir de um conjunto de pesquisas como os de Biroli (2018), que demonstrou a estigmatização de Dilma enquanto politicamente incompetente, de Biscaia (2016) que revelou as tentativas de deslegitimação simbólica que acompanhou a trajetória de Dilma e de Boiteux (2016) que explicitou a misoginia no processo de impeachment percebemos que as conclusões sobre o recorte de análise não são um caso isolado quanto as questões de gênero relacionadas ao tema. Não apenas a IstoÉ mas a mídia como um todo "teve uma participação intensa na propagação da misoginia no processo do golpe” (Rubim \& Argolo, 2018, pg. 152).

A importância de análises sobre diferentes fontes é fundamental para percebermos as repetições de discurso que sedimentam os estereótipos no senso comum. Segundo Landowski (2012) os estereótipos que "uma vez construídos, só farão, uns e outros, reforçarem-se na mesma proporção do uso repetido que deles será feito" (p. 13). Abraham (2002) considera a audiência uma interpretação polissêmica de um texto e analisa os discursos a partir da ideia de que os olhares masculinos são tidos como hegemônicos, e os olhares femininos são subversivos. Isso fica claro após a análise das fotografias, onde Dilma foi retratada em expressões faciais duras ou raivosas, marcadas por uma edição que aumentava o contraste da sombra e acentuava a coloração vermelha do rosto. O mesmo não se pode dizer de Aécio, cuja força masculina foi destacada nas fotografias escolhidas através de ângulos ou edições.

A representação ganha, assim, um valor simbólico por estar em harmonia com um padrão bem explorado de estereótipos da sociedade patriarcal. Por serem revistas muito populares, as consequências desse jornalismo são enormes: "as imagens são poderosas ferramentas de enquadramento porque são menos intrusivas do que as palavras e, como tal, exigem menor carga cognitiva" (Rodriguez \& Dimitrova, 2011, p. 50). Neste sentido, há a tendência a "a aceitar o quadro visual sem questionar" (Rodriguez \& Dimitrova, 2011, p. 50).

Verificamos que a revista IstoÉ usou diversos processos semióticos de conotação como: pose, estética, fotogenia, escolha de objetos e trucagem. As conclusões sobre o uso das ferramentas semióticas e dos estereótipos a elas relacionados apontam para uma produção de efeitos avaliativos negativos relacionados tanto a Dilma como às mulheres em posições de poder a partir de imagens que moldam as interpretações 
sociais excludentes e misóginas. Estas interpretações são formuladas por um processo de produção do poder simbólico, segundo os quais a dimensão espacial e os recortes adquirem uma importância fundamental, pois a "luta de ideologias pode ser caracterizada por uma violência simbólica quando materializada em reportagens e fotografias" (Lima, 2017, p. 12). A análise identificou estereótipos visuais vinculados ao não pertencimento feminino aos espaços públicos de poder, a racionalidade masculina em contraste com a histeria feminina, a vulnerabilidade e solidão das mulheres políticas e vinculações de Dilma à figura de bruxa. Para Ramos, a relação entre Dilma e a mídia é "uma história da relação de poder em uma sociedade machista, racista e classista que despreza as mulheres, duvida da nossa capacidade e inteligência, constrói armadilhas motivadas pelas questões de gênero e misoginia" (Ramos, 2016, p. 241)

Não existe discurso sem sujeito, nem sujeito sem ideologia (Assoni \& Neris, 2014), porém seria precipitado julgar a parcialidade da revista IstoÉ com base apenas nessa análise. Temos sim pistas, pois "deve-se levar em conta as condições de produção/ consumo dos discursos sociais em jogo, examinando-se as determinações responsáveis pelas escolhas conscientes ou não, feitas por ocasião de um engendramento de um discurso ou de um tipo de discurso" (Pinto, 1995, p. 146). Pesquisas futuras devem considerar uma análise longitudinal de várias campanhas eleitorais e focar-se em todas e todos os candidatos, procurando padrões e disrupções de representação.

\section{REFERENCIAS}

Abraham, L. K. (2002). The black woman asmMarker of hypersexuality in western mythology: a contemporary manifestation in the film the scarlet letter. Journal of Communication Inquiry, 26(2), 193-214.

Araujo, C. (2010). Rotas de ingresso, trajetórias e acesso das mulheres ao Legislativo: um estudo comparado entre Brasil e Argentina. Revista Estudos Feministas, 18(2), 567-584.

Assoni, I. M. S., \& Neres, G. M. (2014). Mídia e ideologia: O posicionamento da revista Veja diante da reintrodução das disciplinas de sociologia e filosofia no Ensino Médio. http://cac-php.unioeste.br/eventos/Anais/servico-social/anais

Balandier, G. (1982). O poder em cena. UNB. 
Uma mulher no espaço político: Um estudo comparativo entre as representações

fotográficas de Dilma Roussef e Aécio Neves na mídia tradicional brasileira

Barthes, R. (1956). Mythologies. Seuil.

Barthes, R. (1982). A Mensagem Fotográfica. In Luiz Costa Lima (Org.), Teoria de Cultura de Massa. Paz e Terra.

Baxter, J. (2017). Women leaders and gender stereotyping in the UK press: A poststructuralist approach. London: Palgrave Macmillan

Beauvoir, S. (1960). O segundo sexo: fatos e mitos. Difusão Europeia do Livro.

Biroli, F. (2010). Gênero e política no noticiário das revistas semanais brasileiras: ausências e estereótipos. Cadernos Pagu, no 34, 269-99.

Biroli, F. (2018). Uma mulher foi deposta: sexismo, misoginia e violência política. $O$ golpe na perspectiva de gênero, 1,1 .

Biscaia, C. N. (2016). Um golpe chamado machismo. In C. Proner. et al. (Org.). A resistência ao golpe de 2016, (cap. 17, pp. 86-88.). Bauru: Canal 6.

Boiteux, L. (2016). Misoginia no golpe. In C. Proner, G. Cittadino, M. Tenenbaum, \& W. Ramos Filho (Orgs.), A resistência ao golpe de 2016, (cap. 61, pp. 261-266). Bauru: Canal 6.

Bourdieu, P. (1998). Conferencia do Prêmio Goffman: a dominação masculina revisitada. Papirus.

Braidotti, R. (1991). Patterns of Dissonance. Cambridge: Polity Press.

Briggs, A., \& Burke, P. (2016). Uma História Social da Mídia: de Gutenberg à Internet, (Tradução de Maria Carmelita Pádua Dias). Rio de Janeiro: Jorge Zahar.

Butler, J. P. (2015). Quadros de guerra: quando a vida é passível de luto. Rio de Janeiro: Civilização Brasileira.

Bulawka, H. M. (2012). Gender representations in the Polish press: A feminist critical discourse study, [PhD Thesis]. University of Birmingham.

Debord, G. (1931). Comments on the society of the spectacle. Verso.

Cardoso, C. F., \& Mauad, A. M. (1997). História e Imagem: o caso da fotografia e do cinema. In C. F. Cardoso, \& R. Vainfas (Orgs.), Domínios da História, Ensaios de Teoria e Metodologia. Campus. 
Carniel, F.; Ruggi, L. \& Ruggi, J. O. (2018) Gênero e humor nas redes sociais: a campanha contra Dilma Rousseff no Brasil. Opinião Pública, 24(3), set.-dez., 523-546.

Fairclough, N. (2000). Nova linguagem? Londres: Routledge.

Fairclough, N. (2003). Analysing Discourse. Textual analysis for social research. Abingdon: Routledge, 2003.

Finamore, C. M., \& Carvalho, J. E. C. (2006). Mulheres candidatas: relações entre gênero, mídia e discurso. Revista Estudos Feministas, 14(2), 347-362. ISSN 0104026X. http://dx.doi.org/10.1590/S0104-026X2006000200002.

Flores, T. M. (2012). À esquerda e à Direita: a Representação dos Valores de Gênero nas fotografias de duas deputadas Portuguesas. Revista Media \& Jornalismo, 21.

Flores, G. B. (2017). Neutralidade e silenciamento no discurso jornalístico. In G. B. Flores, N. R. M. Neckel, \& S. M. L. Gallo (Orgs.), Análise de discurso em rede: cultura e mídia. Vol. 3. Campinas: Pontes.

Fresnault-Deruelle, P. (1993). La tête de l'emploi. In Léloquence des images (pp. 3748). Paris: PUF.

Geraldes, E., Ramos, T., Silva, J., Machado, L., \& Negrini, V. (2016). Mídia, Misoginia $e$ Golpe ( $1^{\text {a }}$ ed.). FAC-UnB.

Goffman, E. (2013). A representação do eu na vida cotidiana. Vozes.

Gombrich, E. H. J. (1984). The image and the eye: further studies in the psychology of pictorial representation. Phaidon.

Greimas, A. J. \& Courtes, J. (1979). Dicionário de Semiótica (1ª ed., Vários tradutores). Contexto.

Guimarães, A. S. A. (1999). Classes, raças e democracia. São Paulo: Editora 34.

Hall, S. (1997). The spectable of the 'other'. In S. Hall (Ed.). Representation. Culture representations and signifying practices (pp.223-290). London: Sage-The Open University

Kossoy, B. (1999). Realidades e Ficções na Trama Fotográfica. Ateliê. 
Uma mulher no espaço político: Um estudo comparativo entre as representações

fotográficas de Dilma Roussef e Aécio Neves na mídia tradicional brasileira

Kress, G., \& Van Leeuwen, T. (2006). Reading Images: The Grammar of Visual Design. London: Routledge.

Landowski, E. (2012). Presenças do outro: ensaios de sociossemiótica. Perspectiva.

Ledin, P., \& Machin, D. (2018). Doing visual analysis: From theory to practice. London: Sage.

Leite, M. M. (1993). Retratos de família. Edusp.

Lester, P. (1995). Visual Communication. Images with Messages. Belmont, CA: Wadsworth Publishing Company.

Lima, G. S. (2017). Violência Simbólica na Mídia: Uma análise do processo de impeachment de Dilma Roussef segundo a revista Veja. Jornada Cientifica de Comunicação Social. Universidade do Sagrado Coração

Lima, V. A. (2001). Mídia: Teoria e Política. São Paulo: Editora Fundação Perseu Abramo.

Lipovetsky, G. (1981). O império do efêmero: a moda e seu destino nas sociedades modernas. Cia das Letras.

Lipovetsky, G. (2000). A terceira mulher: permanência e revolução do feminino. Cia das Letras.

Machin, D. (2004) Building the world's visual language: The increasing global importance of image banks in corporate media, Visual Communication, 3 (3), $316-336$.

Machin, D. (2007). Introduction to Multimodal Analysis. London: Arnold.

Machin, D., \& Mayr, A. (2012). How to do Critical Discourse Analysis. Sage.

Mariani, B. (1996). O comunismo imaginário - práticas discursivas da imprensa sobre o PCB (1922 - 1989). Campinas: Unicamp.

Marques, C. J. (2014). A ofensiva de Aécio. IstoÉ Online. https://istoe.com.br/381236_ UMA+TRIBUNA+AS+PROPOSTAS+PARA+O+BRASIL/

Martins, C. (2015). Mulheres, Liderança Política e Media. Lisboa: Alêtheia Editores.

Mauad, A. M. (1996). Através da imagem: Fotografia e história. I Interfaces. Tempo, 1(2), 73-98. 
Mauad, A. M. (2007). O poder em foco - Imagens reservadas de homens públicos, uma reflexão sobre fotografia e representação social. Diálogos: Revista do Departamento de História e do Programa de Pós-Graduação em História, 11, (3), 119-149.

Montezano, C. T., \& Pimenta, F. P. (2016). Análise Semiótica da capa do Cd "Anti" da cantora pop Rihanna. XXI Congresso de Ciências da Comunicação na Região Sudeste. Intercom - Sociedade Brasileira de Estudos Interdisciplinares da Comunicação.

Mota Ribeiro, S. (2005). Imagem. In Ana Gabriela Macedo e Ana Luísa Amaral (Eds.), Dicionário da Crítica Feminista. Porto: Afrontamento.

Naldoni, T. (2012). Controverso e respeitado, Mino Carta continua se reinventando no mercado jornalístico. Revista Imprensa Jornalismo e Comunicação. https:// portalimprensa.com.br/revista_imprensa/conteudo-extra/46542/controverso+ $\mathrm{e}+$ respeitado+mino+carta+continua $+\mathrm{se}+$ reinventando+no+mercado+jornalis tico

Narvaz, M. G., \& Koller, S. H. (2006). Famílias e patriarcado: da prescrição normativa à subversão criativa. Psicologia \& Sociedade, 18(1), 49-55.

Oliveira, A, C. (2004). Semiótica Plástica. Hacker Editora.

Orlandi, E. P. (1996). Interpretação: autoria, leitura e efeitos do trabalho simbólico. Petrópolis: Vozes.

Pacheco, C. A. D. (2008). Veja FHC, Veja Lula: análise dos discursos de capa da revista Veja sobre os dois candidatos à presidência. Anagrama, 1(3), 1-16.

Pardellas, S. (2016). Uma presidente fora de si - IstoÉ Independente. https://istoe.com. br/450027_UMA+PRESIDENTE+FORA+DE+SI/

Picado, B. (2009). Das feições do cargo ao face a face pela imagem: poética do retrato fotográfico na política. Revista da Associação Nacional dos Programas de PósGraduação em Comunicação|E-compós, 12(3).

Pinto, M. J. (1995). Semiologia e imagem. Compôs-A encenação dos sentidos, 141-157.

Ramos, L. de S. (2016) Nilma Lino Gomes. In E. C. Geraldes, T. R. Ramos, J. D. Silva, L. M. Machado, \& V. Negrini (Orgs.). Mídia, misoginia e golpe (p. 237-241). Brasília, DF: FAC Livros. 
Uma mulher no espaço político: Um estudo comparativo entre as representações

fotográficas de Dilma Roussef e Aécio Neves na mídia tradicional brasileira

Rodriguez, L.; Dimitrova, D. V. (2011). The levels of visual framing. Journal of Visual Literacy, 30(1), 48-65.

Rose, G (2001). Visual methodologies. Londres: Sage.

Rubim, L. S. O., \& Argolo, F. (2018). O Golpe na perspectiva de Gênero. Edufba.

Santaella, L. (2002). Semiótica Aplicada. Thomson.

Scott J. W. (1988). Gender and the politics of history. New York: Columbia University Press.

Scott, J. (1995). Gênero: uma categoria útil de análise histórica. Educação \& realidade, 20(2).

Simas Filho, M. (2013). “Temos um país à deriva em busca de um gestor”. IstoÉ Independente. https://istoe.com.br/295801_TEMOS+UM+PAIS+A+DERIVA+ $\mathrm{EM}+\mathrm{BUSCA}+\mathrm{DE}+\mathrm{UM}+\mathrm{GESTOR}+1$

Simões, R. B. (2017). Do escrutínio dos media aos media sob escrutínio: estereótipos de género no espaço público mediatizado. In R. B. Simões, C. Serrano, S. Neto, \& J. Miranda (Orgs.), Pessoas e ideias em trânsito: percursos e imaginários (pp. 13-35). Imprensa da Universidade de Coimbra.

Toral, A. (2001). Imagens em Desordens. A Iconografia da Guerra do Paraguai. Edusp. Van Dijik. (2015). Discurso das elites e racismo institucional. In Lara \& Lamberti (Orgs.) Discurso e desigualdade social (pp. 31-48.). São Paulo: Contexto.

Volosinov, V. N. (1986). Marxism and the philosophy of language. Cambridge, MA: Harvard University Press

Walton, K. L. (1984). Transparent pictures: On the nature of photographic realism. Critical inquiry, 11(2), 246-277.

Young, I. M. (2006). “Representação política, identidade e minorias”. Lua Nova, 67, 139-190. 